\title{
UTILIZAÇÃO DE MANIPUEIRA E URINA DE VACA COMO FONTE DE ADUBAÇÃO PARA A CULTURA DO PINHÃO MANSO (Jatropha curcas)
}

\author{
Fábio Agra de Medeiros Nápoles* \\ José Thyago Aires Souza** \\ Suenildo Jósemo Costa Oliveira*** \\ Filipe Travassos Montenegro**** \\ Carlos Alberto Vieira de Azevedo ${ }^{* * * * *}$
}

RESUMO: O pinhão-manso (Jatropha curcas L.) é um arbusto pertencente à família Euphorbiaceae, amplamente cultivada nos países tropicais. Objetivou-se com este trabalho analisar os efeitos do uso da manipueira e da urina de vaca sobre as características de crescimento do pinhão-manso. $\mathrm{O}$ experimento foi desenvolvido em condições de campo, de janeiro a dezembro de 2010, no CCAA, Campus II da UEPB no município de Lagoa Seca - PB. Foi utilizado no experimento, o esquema de análise fatorial $5 \times 5$, em um delineamento experimental de blocos ao acaso com 25 tratamentos e 4 repetições por tratamento, divididos em 4 blocos, utilizando diferentes volumes de calda de urina de vaca e manipueira. A aplicação de $1000 \mathrm{ml}$ do biofertilizante a base de urina de vaca, proporcionou incremento no diâmetro caulinar de 4,75\%, no número de folhas de $18,70 \%$ e na área foliar de 837,67 \%, quando comparados a testemunha, o uso de $1000 \mathrm{ml}$ da calda com manipueira, proporcionou um aumento no número de folhas e na área foliar nas plantas de pinhão-manso de $53,48 \%$ e 414,02\%, respectivamente, quando comparado ao menor valor obtido, a interação da urina de vaca com $1000 \mathrm{ml}$ da calda com manipueira proporcionou um incremento em diâmetro caulinar de $23,53 \%$ em relação ao menor valor e em área foliar de 543,01\%. Pode-se concluir que os diferentes volumes dos biofertilizantes com urina de vaca e manipueira, influenciaram no crescimento das plantas de pinhão-manso durante os 360 dias, exceto na variável altura das plantas.

PALAVRAS-CHAVE: Oleaginosa; Fertirrigação; Sustentabilidade; Meio ambiente.

Docente Doutor no Departamento de Ciências Agrárias e Ambientais da Universidade Estadual da Paraíba (UEPB), Paraíba, Brasil.

** Programa de Pós-Graduação em Agronomia (PPGA) da Universidade Federal da Paraíba (UFPB), Areia, Paraíba, Brasil; E-mail de correspondência: thyago.agro@hotmail.com

*** Docente Doutor do Departamento de Ciências Agrárias e Ambientais Universidade Estadual da Paraíba (UEPB), Paraíba, Brasil.

**** Agroecólogo; Universidade Estadual da Paraíba (UEPB), Paraíba, Brasil

${ }^{* * * * *}$ Docente Doutor da Universidade Federal de Campina Grande (UFCG), Paraíba, Brasil. 


\title{
MANIPUEIRA AND COW URINE AS A FERTILIZING SOURCE FOR JATROPHA (Jatropha curcas)
}

\begin{abstract}
The Jatropha curcas L. is a shrub of the family Euphorbiaceae widely cultivated in tropical countries. Current study analyzes the effects of the manioc milky juice, known as manipueira in Brazil, and cow urine on the growth of jatropha. The experiment was conducted between January and December 2010 at CCAA, Campus II of UEPB, in Lagoa Seca PB Brazil. The assay had a 5 x 5 factorial design and randomized blocks with 25 treatments and 4 replications per treatment, divided into 4 blocks, with different volumes of cow urine and manipueira broth. The application of $1000 \mathrm{ml}$ of the biofertilizer with cow urine increased the stem diameter by $4.75 \%$, number of leaves by $18.70 \%$ and foliar area by $837.67 \%$ when compared to control. Further, $1000 \mathrm{ml}$ of manipueira broth increased the number of leaves and the foliar area of the jatropha plant by $53.48 \%$ and $414.02 \%$, respectively when compared to the lowest rate. The interaction of cow urine and $1000 \mathrm{ml}$ of manipueira broth increased the stem diameter by $23.53 \%$ when compared to the lowest rate and by $543.01 \%$ of the foliar area. Results show that different volumes of biofertilizers with cow urine and manipueira affected the growth of jatropha plants during 360 days, except for the variable plant height.
\end{abstract}

KEY WORDS: Oleaginosa; Fertirrigation; Sustainability; Environment.

\section{INTRODUÇÃO}

O pinhão-manso é uma espécie perene pertencente à família das Euforbiáceas, a mesma família da mamona, mandioca e seringueira, amplamente distribuído em áreas tropicais e subtropicais com potencial para a produção de biocombustível (LAVIOLA; DIAS, 2008).

A espécie Jatropha curcas L. caracteriza-se pela fácil propagação, rápido crescimento, elevado teor de óleo, podendo ser cultivada em áreas de baixa e alta precipitação. Sua fase reprodutiva se inicia a partir do décimo mês após o plantio, período em que ocorre aumento progressivo de produção até o terceiro ou quarto ano, quando se estabiliza, podendo chegar a quatro metros de altura e manter o período produtivo por até 40 anos, esta oleaginosa ainda não é utilizada para alimentação humana ou animal, sendo considerado uma matéria prima potencial 
para o Programa Nacional de Produção e uso de Biodiesel (PNPB) (ARRUDA et al., 2004; OLIVEIRA et al., 2007; SUJATHA et al., 2009; EMBRAPA AGROENERGIA, 2009; MARTINS et al., 2010).

O desenvolvimento do pinhão-manso é favorecido em regiões tropicais cuja precipitação anual esteja acima de $600 \mathrm{~mm}$ e, acima dos $1000 \mathrm{~mm}$ anuais, o nível ideal de precipitação para que possam ser atingidas altas produtividades. Avaliando a primeira colheita, Drumond et al. (2010) obtiveram produtividade de $871 \mathrm{~kg} \mathrm{ha}^{-1} \mathrm{em}$ plantas irrigadas e, em regime normal de chuvas (sequeiro), $246 \mathrm{~kg}$ ha-1, a produção é drasticamente afetada com valores anuais inferiores a $600 \mathrm{~mm}$.

Para se obter alta produtividade de frutos, a planta necessita de água e exige solos férteis e com boas condições físicas. Logo, a irrigação, a correção da acidez e da fertilidade do solo, são fatores decisivos para se obter sucesso e lucratividade com esta cultura (CHAVES et al., 2009; SCHIAVO et al., 2010).

$\mathrm{Na}$ atualidade entanto, não é só produzir intensivamente visando os lucros máximos que a cultura pode fornecer é preciso levar em conta o conceito de sustentabilidade, que está diretamente ligado a mudança de rumo da produção energética mundial, que busca combustíveis renováveis. Surgem nos diversos setores sociais discussões em torno da "agricultura sustentável", cujo conceito não pode ter o aspecto estático, comumente implícito no tempo, pelo qual os sistemas agrícolas são considerados sustentáveis, quando a produção é pensada como fator isolado.

$\mathrm{Na}$ agricultura moderna, cada vez mais, há necessidade de se promover modelos alternativos ou a implementação de técnicas dentro dos sistemas já existentes, no sentido de garantir a viabilidade agrícola sob seus diversos aspectos. Frente a essa problemática, apresenta-se o uso de biofertilizantes líquidos na agricultura, que vem mostrando bons resultados em algumas formulações já testadas e que podem também ser aplicadas de forma alternativa na proteção de plantas. Essa estratégia é indicada principalmente para as pequenas propriedades, onde os recursos financeiros e tecnológicos são escassos, aproveitando-se subprodutos da agropecuária que muitas vezes são descartados. (MEDEIROS; LOPES, 2006).

Dois subprodutos da agropecuária que estão apresentando resultados cientificamente comprovados, como biofertilizantes, são a manipueira e a urina de vaca, além de atuarem no controle preventivo de doenças e de pragas. Com isso, 
foram analisados os efeitos da manipueira e urina de vaca, aplicadas via adubação foliar e no solo, no cultivo do pinhão-manso, numa perspectiva de produção agroecológica ao alcance do agricultor familiar.

Tendo em vista o exposto, objetivou-se com este trabalho analisar os efeitos do uso da manipueira e da urina de vaca sobre as características de crescimento do pinhão-manso.

\section{MATERIAL E MÉTODOS}

O experimento foi desenvolvido em condições de campo, de janeiro a dezembro de 2010, numa área agrícola pertencente ao Centro de Ciências Agrárias e Ambientais (CCAA), Campus II da Universidade Estadual da Paraíba (UEPB), Lagoa Seca, Paraíba, Brasil, com as seguintes coordenadas geográficas: latitude $7^{\circ} 09^{\prime} \mathrm{S}$; longitude $35^{\circ} 52^{\prime}$ W e altitude $634 \mathrm{~m}$ (Figura 1).

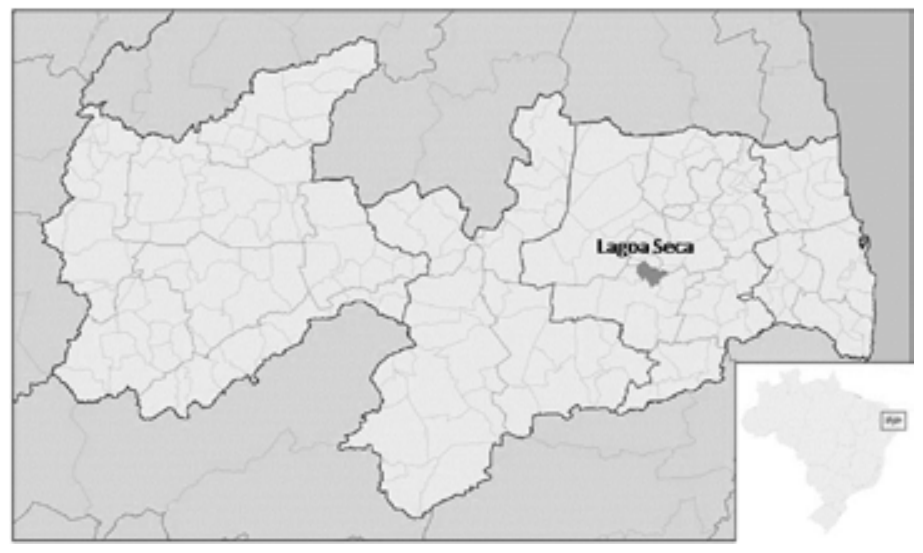

Figura 1. Localização de Lagoa Seca, no Estado da Paraíba

O solo da área experimental é classificado como NEOSSOLO REGOLÍTICO EUTRÓFICO, moderadamente declivoso, profundo, de classe textural franco arenosa, boa drenagem e fertilidade moderada. Quanto à salinidade é classificado como normal.

Foi utilizado no experimento, o esquema de análise fatorial 5 × 5, em um 
delineamento experimental de blocos ao acaso com 25 tratamentos e 4 repetições por tratamento, divididos em 4 blocos. 0 tratamento 1 representou a testemunha, não se submetendo a aplicação de urina de vaca e manipueira. Nos tratamentos 2,3 , 4 e 5 se utilizou 250, 500, 750 e $1000 \mathrm{ml}$ da calda com manipueira respectivamente e a urina de vaca não foi aplicada. Nos tratamentos T6 a T10 foram utilizados os volumes fixos da calda com urina de vaca de $250 \mathrm{ml}$, enquanto se seguiu a mesma sequência anterior em relação a manipueira: 0, 250, 500, 750 e $1000 \mathrm{ml}$ de calda respectivamente. Nos tratamentos T11 a T15 o volume fixo da calda com urina de vaca foi de $500 \mathrm{ml}$, e novamente a mesma sequência de aplicação da calda com manipueira: 0, 250, 500, 750 e $1000 \mathrm{ml}$ respectivamente. Nos tratamentos T16 a T20 o volume fixo da calda com urina de vaca foi de $750 \mathrm{ml} \mathrm{e}$ a quantidade de manipueira seguiu a mesma sequência crescente anterior. Os tratamentos T21, T22, T23, T24 e T25 continham $1000 \mathrm{ml}$ da calda com urina de vaca e $0,250,500,750$ e $1000 \mathrm{ml}$ da calda com manipueira respectivamente.

A área do experimento foi previamente preparada em dezembro de 2009, com uma aração. Na produção das mudas, foram utilizadas sementes oriundas do acesso da EPAGRI-MG, as quais foram semeadas em sacos de polietileno $(10 \mathrm{~cm}$ de diâmetro x $15 \mathrm{~cm}$ de altura), contendo substrato composto por duas partes de solo e uma de húmus de minhocas cedido pelo Centro de Ciências Agrárias e Ambientais da UEPB. Enquanto as plantas germinavam e cresciam, as covas foram abertas nas dimensões de $40 \mathrm{~cm}$ x $40 \mathrm{~cm}$ x $40 \mathrm{~cm}$ e adubadas com $5 \mathrm{Kg}$ de esterco bovino, de acordo com sugestão de Beltrão (2007).

Foi instalado o sistema de irrigação localizada, composto de um conjunto eletrobomba, uma tubulação principal de $110 \mathrm{~m}$ no centro da área com registros de saída espaçados de 6 em $6 \mathrm{~m}$, e as mangueiras irrigavam cada planta. As irrigações foram manejadas e controladas mediante uso de planilha eletrônica.

A coleta e preparo da calda com urina de vaca baseou-se na metodologia proposta pela PESAGRO-RIO (2001). A proporção de diluição da urina foi de 10 $\%$. A urina foi coletada em vacas leiteiras mestiças, criadas em sistema de semiconfinamento em pequenas propriedades rurais circunvizinhas. Antes da aplicação, a urina passou por um período de repouso durante três dias em recipiente plástico hermeticamente fechado (EMATERCE, 2000). A manipueira foi coletada em uma 
casa de farinha da região, após a prensa da mandioca e colocada em repouso por pelo menos uma semana, em recipientes plásticos hermeticamente fechados para diminuir a sua toxicidade quanto ao teor de ácido cianídrico.

A proporção de diluição da manipueira foi de $50 \%$ e os volumes aplicados em cada tratamento. Para melhor aproveitamento, a aplicação das caldas com urina de vaca e manipueira nas plantas, realizou-se mensalmente, no período da manhã, até 10 horas e no período da tarde a partir de 16 horas.

Foram realizadas avaliações de diâmetro caulinar (DC) e área foliar (AF) bimestralmente, em todas as plantas, a partir dos 60 dias, com leituras sucessivas de $120,180,240,300$ e 360 dias.

Os dados obtidos foram tabulados e submetidos à análise de variância, utilizando o software SAS (Statistical Analysis Sistem, versão 6.12, 1997) sendo interpretados quantitativamente e qualitativamente. Quando se constatou efeito significativo na análise de variância, foi utilizada a análise de regressão para determinação do modelo matemático. Sendo que, na escolha do melhor modelo de regressão foram adotados os seguintes critérios em ordem de importância: regressão significativa, coeficiente de determinação $\left(\mathrm{r}^{2}\right)$ e explicação biológica em consonância com o modelo estatístico.

\section{RESULTADOS E DISCUSSÃO}

O maior valor do diâmetro caulinar $(73,50 \mathrm{~mm})$ foi obtido quando se adicionou urina de vaca dentro de $1000 \mathrm{ml}$ da calda com manipueira, isto significa um aumento de $23,53 \%$, comparado ao valor $59,5 \mathrm{~mm}$, obtido quando se utilizou $500 \mathrm{ml} \mathrm{da}$ calda com manipueira. O comportamento da curva de regressão apresentou tendência quadrática, demonstrando que a adição da urina de vaca a $1000 \mathrm{ml}$ da calda com manipueira, favorece o aumento do diâmetro do caule da planta de pinhão-manso (Figura 2). 


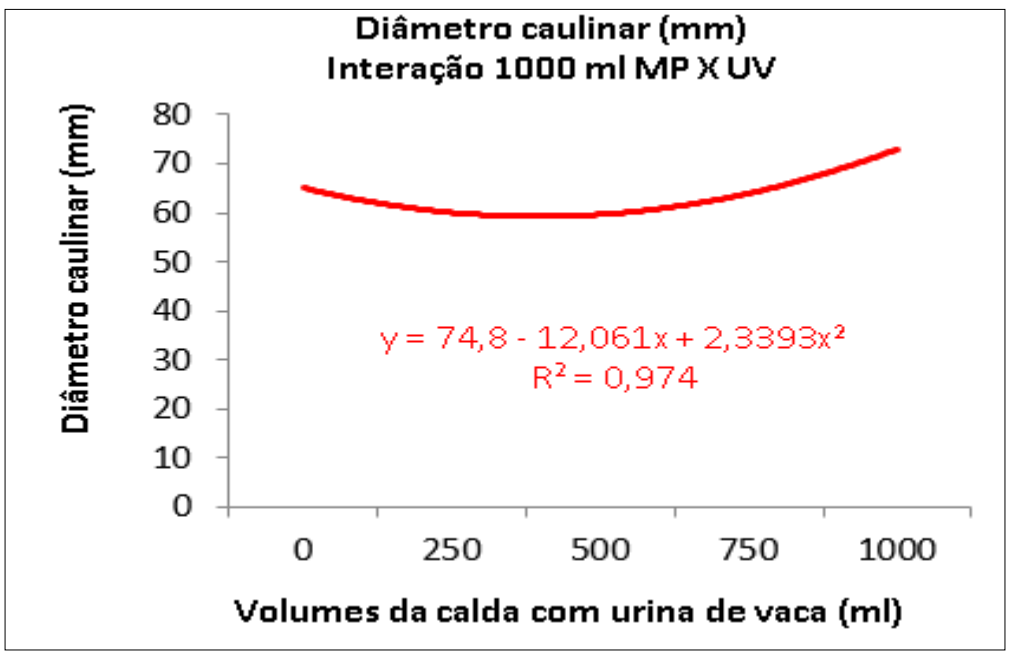

Figura 2. Análise de regressão do diâmetro caulinar da planta do pinhão-manso aos 360 dias, em função dos volumes da calda com urina de vaca, dentro de $1000 \mathrm{ml}$ da calda com manipueira $(p<0,05$ e $p<0,01)$. Lagoa Seca, PB.

Esses efeitos foram observados por Nascimento et al. (2008), que verificaram a influência da adubação nitrogenada no crescimento inicial do pinhão-manso, utilizando ureia nas dosagens de 0, 60, 90 e $120 \mathrm{~kg}$. ha ${ }^{-1}$ de nitrogênio, concluindo que a maior dosagem, proporcionou os maiores valores para as variáveis altura, diâmetro caulinar e área foliar. Conforme Souza et al. (2010), a urina de vaca pode ser utilizada para fertirrigação do pinhão-manso, mas com cuidado em sua diluição e modo de aplicação.

Para a variável área foliar, o maior valor encontrado foi de $26.108,46 \mathrm{~cm}^{2}$, quando acrescentou-se urina de vaca dentro de $1000 \mathrm{ml}$ da calda com manipueira, aumento de 543,01\% em relação ao menor valor de 4.060,30 $\mathrm{cm}^{2}$, obtido quando se utilizou apenas a manipueira. (Figura 3).

No estudo da análise de regressão em função da adição da urina de vaca (UV), nos diferentes volumes da calda com manipueira (MP), a variável área foliar apresentou efeito significativo. As linhas de tendências foram quadráticas (Figuras $3 \mathrm{~A}, 3 \mathrm{~B}, 3 \mathrm{D}$ e $3 \mathrm{E}$ ) e cúbica (Figura $3 \mathrm{C}$ ), porém, o melhor resultado foi quando adicionou-se $1000 \mathrm{ml}$ da calda com urina de vaca (UV) dentro de $1000 \mathrm{ml}$ da calda com manipueira (MP) (Figura $3 \mathrm{E}$ ). 

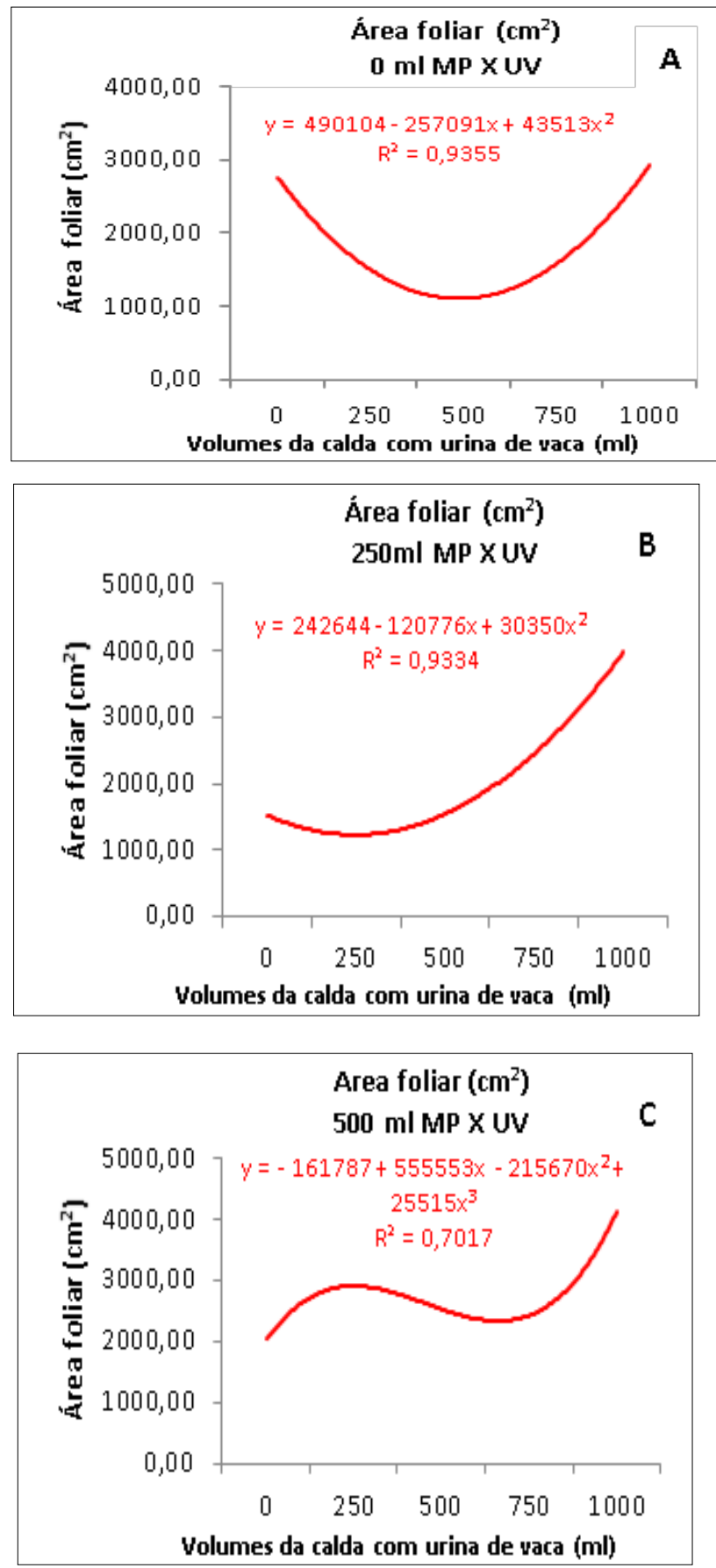

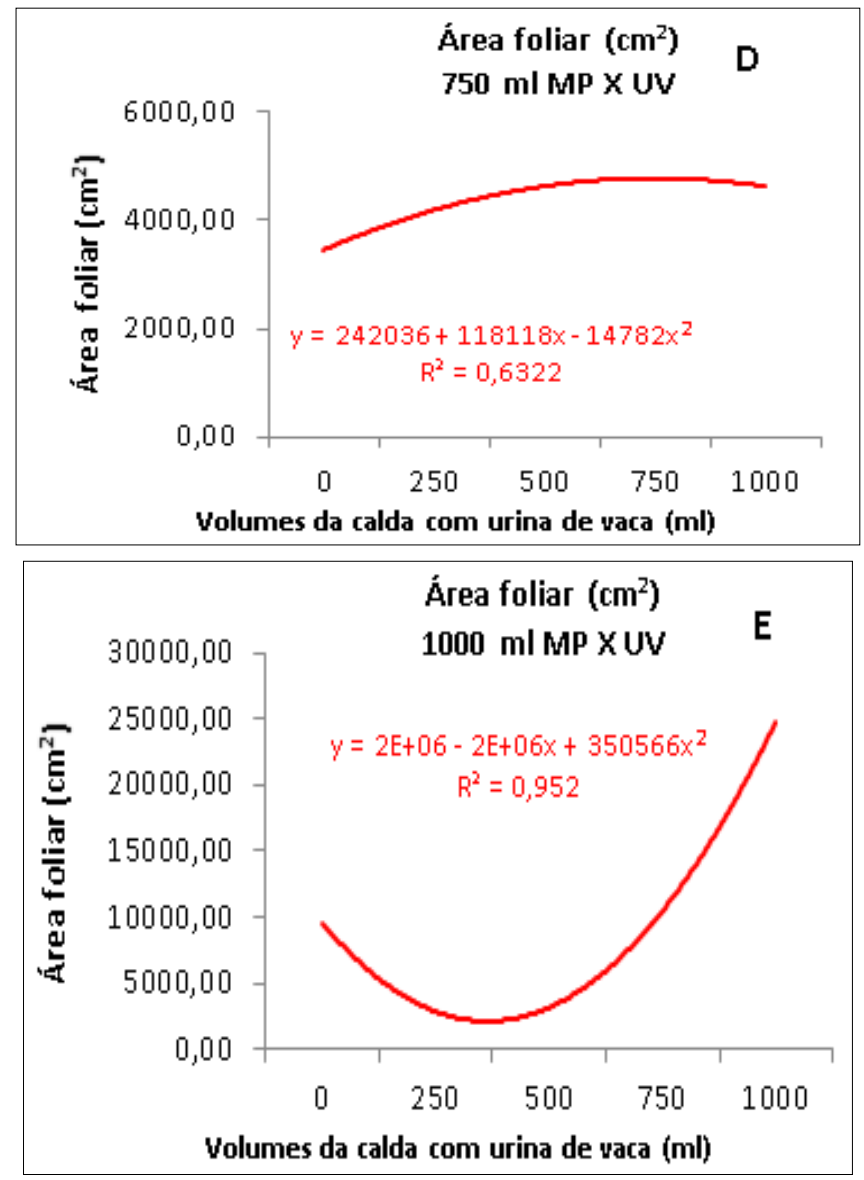

Figura 3. Análise de regressão da área foliar do pinhão-manso aos 360 dias, sem manipueira (A), $250 \mathrm{ml}$ (B), $500 \mathrm{ml}(\mathrm{C}), 750 \mathrm{ml}$ (D) e $1000 \mathrm{ml}$ de manipueira, respectivamente, em função do uso da urina de vaca, $(p<0,05$ e $p<0,01)$. Lagoa Seca, PB.

Estes resultados vão de acordo com Taiz e Zeiger, (2013), fisiologicamente a resposta da planta ao crescimento e multiplicação celular dar-se por dois meios, o alongamento celular provocado pela absorção d ' água e a participação do nitrogênio. Possivelmente, $\mathrm{O}$ uso da urina de vaca (fonte de nitrogênio) e da manipueira (facilitador da absorção de água, devido aos solutos presentes e principalmente potássio) agiram na fisiologia das plantas que compuseram o experimento. De acordo com Larcher (2004), a energia que a planta requer para o seu crescimento e desenvolvimento provém da atividade fotossintética, adubações e imobilização de 
minerais de reserva da planta. Assim, de acordo com Ferreira (1995), a urina de vaca é um biofertilizante rico em nutrientes principalmente em $\mathrm{N}$ e $\mathrm{K}$, e pode ser usada como adubo e defensivo natural na agricultura. Porém as composições mais importantes na urina de bovinos adultos são a ureia e amônia que ocorrem com grande variação em suas concentrações em função da alimentação animal. O que, acordo com Jarvis et al. (1989), a ureia representa 75 \% de nitrogênio total da urina de bovinos.

Souza et al. (2010), verificaram que houve efeito significativo das doses de urina de vaca para as variáveis: fitomassa epígea e hipógea, fitomassa total e relação fitomassa epígea/hipógea.

Como a interação de urina de vaca com manipueira foi significativa pelo Teste F, foi realizada uma análise de variância para estudar, também, o efeito da manipueira dentro de cada volume da calda com urina de vaca. Com base nos dados obtidos, se realizou a análise estatística para as variáveis diâmetro caulinar e área foliar, apresentada na Tabela 1.

Tabela 1. Resumo da análise de variância (Quadrado Médio) das variáveis: diâmetro caulinar e área foliar do pinhão-manso, aos 360 dias, em função da manipueira, dentro de cada volume da calda com urina de vaca. Lagoa Seca, PB

(continua)

\begin{tabular}{cccc}
\hline \multirow{2}{*}{ FV } & GL & Diâmetro caulinar & Área foliar \\
\cline { 3 - 4 } & & $\mathrm{mm}$ & $\mathrm{cm}^{2}$ \\
\hline MP dentro de UV 0 & 4 & $8,95^{\mathrm{ns}}$ & $328.313 .269,00^{* *}$ \\
Efeito Linear & 1 & $3,60^{\mathrm{ns}}$ & $693.294 .440,33^{* *}$ \\
Efeito Quadrático & 1 & $16,07^{\mathrm{ns}}$ & $590.660 .309,36^{* *}$ \\
Efeito Cúbico & 1 & $14,40^{\mathrm{ns}}$ & $16.804 .996,32^{\mathrm{ns}}$ \\
Falta de Ajuste & 1 & $1,73^{\mathrm{ns}}$ & $12.493 .330,00^{\mathrm{ns}}$ \\
MP dentro de UV 250 & 4 & $16,30^{\mathrm{ns}}$ & $102.211 .726,82^{* *}$ \\
\hline Efeito Linear & 1 & $40,00^{\mathrm{ns}}$ & $367.437 .307,67^{* *}$ \\
Efeito Quadrático & 1 & $7,14^{\mathrm{ns}}$ & $4.414 .592,63^{\mathrm{ns}}$ \\
Efeito Cúbico & 1 & $5,63^{\mathrm{ns}}$ & $36.768 .810,59^{\mathrm{ns}}$ \\
\hline
\end{tabular}


Conclusão

\begin{tabular}{cccc}
\hline FV & GL & Diâmetro caulinar & Área foliar \\
\cline { 3 - 4 } & & $\mathrm{mm}$ & $\mathrm{cm}^{2}$ \\
\hline MP dentro de UV 500 & 4 & $119,33^{* *}$ & $111.542 .893,64^{* *}$ \\
\hline Efeito Linear & 1 & $324,90^{* *}$ & $367.517 .630,64^{* *}$ \\
Efeito Quadrático & 1 & $103,14^{*}$ & $1.721 .499,27^{\text {ns }}$ \\
Efeito Cúbico & 1 & $12,10^{\text {ns }}$ & $49.192 .260,52^{\text {ns }}$ \\
Falta de Ajuste & 1 & $37,16^{\text {ns }}$ & $27.740 .184,12^{\text {ns }}$ \\
MP dentro de UV 750 & 4 & $56,17^{\text {ns }}$ & $195.462 .273,49^{* *}$ \\
\hline Efeito Linear & 1 & $50,63^{\text {ns }}$ & $666.751 .943,46^{* *}$ \\
Efeito Quadrático & 1 & $90,02^{\text {ns }}$ & $102.263 .708,14^{* *}$ \\
Efeito Cúbico & 1 & $10,00^{\text {ns }}$ & $12.647 .741,97^{\text {ns }}$ \\
Falta de Ajuste & 1 & $74,06^{\text {ns }}$ & $185.700,40^{\text {ns }}$ \\
MP dentro de UV 1000 & 4 & $39,08^{\text {ns }}$ & $3.961 .782 .771,49^{* *}$ \\
\hline Efeito Linear & 1 & $112,23^{*}$ & $9.023 .405 .153,46^{* *}$ \\
Efeito Quadrático & 1 & $0,16^{\text {ns }}$ & $4.777 .918 .620,37^{* *}$ \\
Efeito Cúbico & 1 & $3,03^{\text {ns }}$ & $1.871 .209 .454,82^{* *}$ \\
Falta de Ajuste & 1 & $40,89^{\text {ns }}$ & $174.597 .857,29^{* *}$ \\
Resíduo & 72 & 27,97 & $12.544 .904,19$ \\
CV (\%) & & 8,17 & 26,15 \\
\hline
\end{tabular}

Notas: $(* *),(*)$ e (ns) - Significativo a 1\%, a $5 \%$ de probabilidade e não significativo, respectivamente (Teste F). UV0 $=0 \mathrm{ml}$ Urina; UV250 $=250 \mathrm{ml}$ Urina; UV500 $=500 \mathrm{ml}$ de Urina; UV750 $=750$ $\mathrm{ml}$ Urina; UV1000 $=1000 \mathrm{ml}$ de Urina

Nos dados da Tabela 1, percebe-se que para a variável diâmetro caulinar do pinhão-manso, houve diferença significativa quando se utilizou manipueira dentro de $500 \mathrm{ml}$ e $1000 \mathrm{ml}$ da calda com urina de vaca, o mesmo não acontecendo para os outros volumes. No entanto, para a variável área foliar, a interação foi significativa entre a manipueira e todos os volumes da calda com urina de vaca.

Segundo a PESAGRO-RIO (1999), o potássio é um dos principais componentes da urina de vaca, tornando-se de fundamental importância para 0 
desenvolvimento das plantas, pois o K é o elemento químico que aparece em maior quantidade e atua na planta aumentando o aproveitamento de água, tornando as paredes celulares dos tecidos resistentes e aumentando a eficiência da adubação (PESAGRO-RIO, 1999). Já Gadelha (2001) relata sobre o elevado teor de nitrogênio, potássio, cloro, enxofre, sódio, fenóis e no ácido indolacético na urina de vaca, tornando-a um excelente biofertilizante para as culturas.

Quimicamente, a manipueira sustenta a potencialidade como fertilizante, haja vista sua riqueza em potássio, nitrogênio, magnésio, fósforo, cálcio, enxofre, e outros micronutrientes (CARDOSO, 2005). Fioretto (1987), utilizando a manipueira na fertirrigação constatou que a aplicação de doses crescentes de manipueira resulta em aumento de fósforo e potássio, assim também como magnésio trocável na solução de solo, mostrando-se eficiente na fertirrigação de milho e algodão.

No estudo do desdobramento da calda de manipueira dentro de cada volume da calda com urina de vaca, o maior valor absoluto em relação às médias do diâmetro caulinar da planta de pinhão-manso foi $73,50 \mathrm{~mm}$, obtido quando se utilizou manipueira dentro de $1000 \mathrm{ml}$ da calda com urina de vaca, isto significa um incremento de $22,5 \%$, em relação ao menor valor $(60,0 \mathrm{~mm})$, quando se aplicou manipueira dentro de $500 \mathrm{ml}$ da calda com urina de vaca.

No estudo de regressão, em função do uso da manipueira dentro dos volumes da calda com urina de vaca, para a variável diâmetro caulinar da planta do pinhão-manso aos 360 dias, verificou-se que houve efeito significativo (Figura 4), apresentando uma tendência quadrática, quando se aplicou manipueira dentro de $500 \mathrm{ml}$ e linear quando se aplicou $1000 \mathrm{ml}$ da calda com urina de vaca (Figuras $4 \mathrm{~A}$ e 4 B).

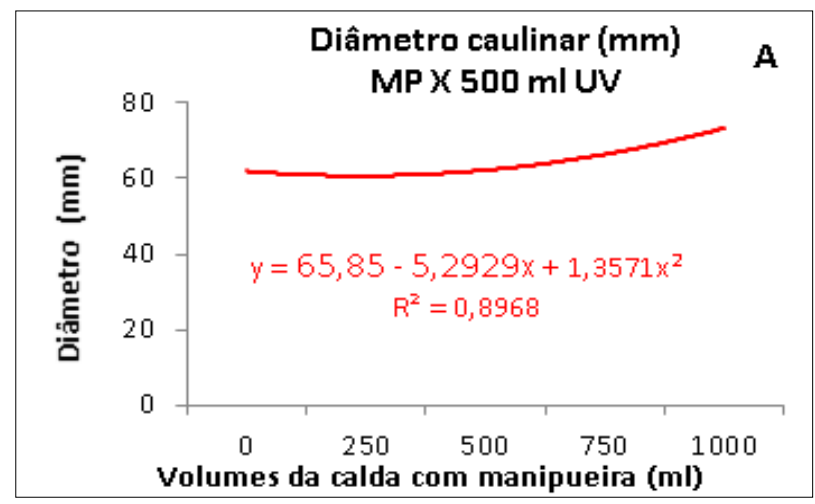




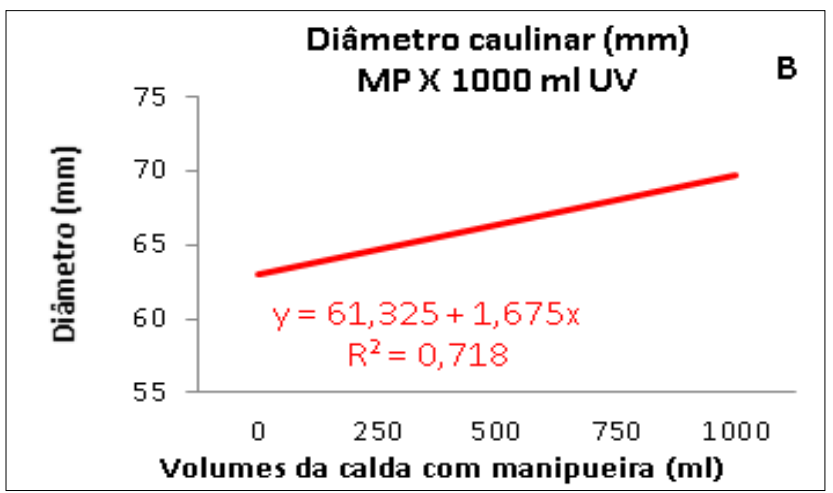

Figura 4. Análise de regressão do diâmetro caulinar do pinhão-manso aos 360 dias, em função da adição de manipueira dentro dos respectivos volumes da calda com urina de vaca: $500 \mathrm{ml}$ (A) e $1000 \mathrm{ml}(\mathrm{B}),(p<0,05$ e $p<0,01)$. Lagoa Seca, PB.

Em relação a utilização da manipueira como biofertilizante, estudos realizados por Vieites e Brinholi (1994), verificaram respostas positivas na utilização da manipueira, nas doses de 60 e $120 \mathrm{~m}^{3} \mathrm{ha}^{-1}$ associadas à adubação mineral, na cultura da mandioca, com o aumento do comprimento e diâmetro das raízes e elevação da produtividade.

Santos et al. (2010), afirmaram que a manipueira pode ser utilizada como fonte de potássio, desde que suas doses sejam ajustadas.

Segundo Silva et al. (2008), verificando a aplicação de cinza de casca de arroz e manipueira na cultura da aveia, o tratamento que apresentou maior produção foi à combinação correspondente a $80 \mathrm{~mm}$ de manipueira associados a $30 \mathrm{t}^{-\mathrm{ha}^{-1}}$ de cinza de casca de arroz, resultando numa produção equivalente a $23.941,7 \mathrm{~kg} \mathrm{ha}^{-1}$.

Para a variável área foliar do pinhão-manso, o maior valor médio foi de $26.108,46 \mathrm{~cm}^{2}$, quando se utilizou manipueira dentro de $1000 \mathrm{ml}$ da calda com urina de vaca, representando um aumento de 837,67\% em relação ao valor de $2.784,39$ $\mathrm{cm}^{2}$, obtido quando não se utilizou manipueira dentro da urina de vaca.

No estudo de regressão em função do uso da manipueira dentro dos volumes da calda com urina de vaca, para a variável área foliar da planta do pinhãomanso aos 360 dias, verificou-se que houve efeito significativo (Figura 5). 

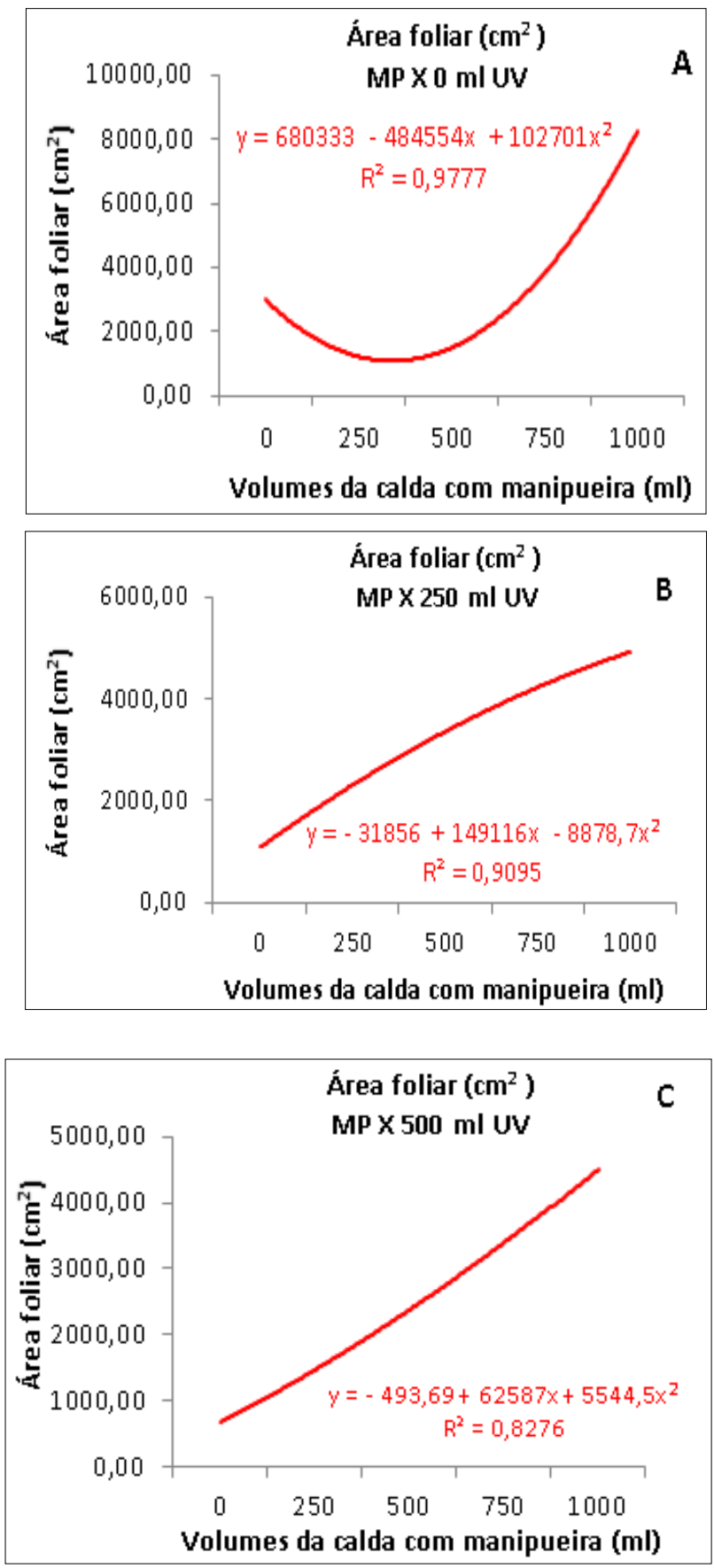

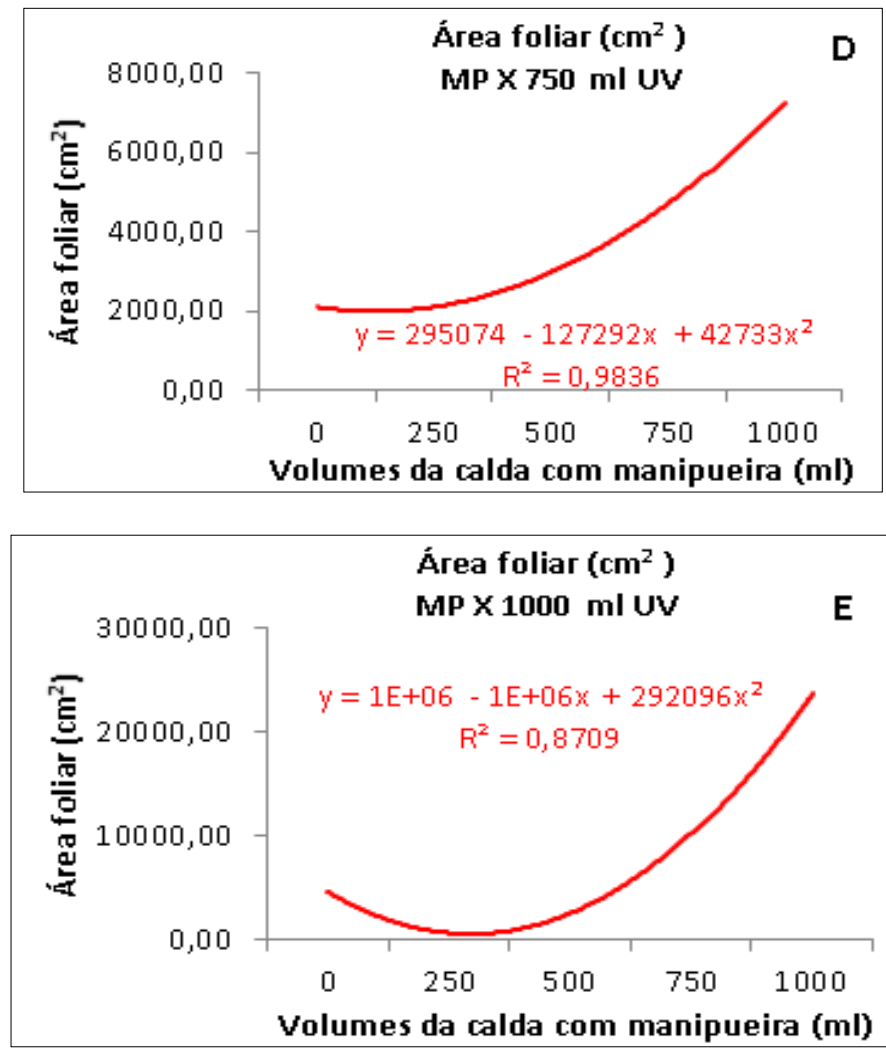

Figura 5. Análise de regressão de área foliar da planta de pinhão-manso aos 360 dias, com manipueira e sem aplicação de urina de vaca (A), com manipueira e $250 \mathrm{ml}$ (B), $500 \mathrm{ml}$ (C), $750 \mathrm{ml}$ (D), 1000 (E) da calda com urina de vaca, respectivamente, $(p<0,05$ e $p<0,01)$, Lagoa Seca, PB.

Estes resultados corroboram com estudos realizados por Ferreira (1995); Lima et al. 2006; Lima (2010) e Souza et al. (2010), e vários outros autores, que ao estudarem a adubação do pinhão-manso concluíram que as variáveis de crescimento são influenciadas diretamente pelo uso de adubos orgânicos.

Estudos realizados por Souza et al. (2010), verificaram na avaliação da fitomassa epígea e hipógea em mudas de mamoneira, sob diferentes dosagens de urina de vaca que este tipo de adubação promoveu o aumento da produção de fitomassa.

Conforme Medeiros et al. (2010), em estudos sobre a produção de mudas de pinhão-manso produzidas em diferentes fontes de matéria orgânica, concluíram que 
o esterco bovino proporcionou melhor crescimento sobre as mudas desta planta e quando realizado o aumento da dose de fertilizantes orgânicos no substrato, houve maior incremento do número de folhas e da área foliar das mudas de pinhão-manso, independente da fonte utilizada.

Autores como Oliveira et al. (2004), Cesar et al. (2007), Guimarães et al. (2008), Albuquerque et al. (2009), Ferreira et al. (2010), e Souza et al. (2010), estudaram e suas conclusões corroboram com os resultados obtidos das variáveis de crescimento do pinhão-manso aos 360 dias.

Segundo Malavolta (2008), as funções do potássio na planta são: economia de água, abertura e fechamento de estômatos, fotossíntese, ativação de enzimas e transporte de carboidratos fonte de dreno. Já Nascimento et al. (2010), em estudo da adubação potássica, no crescimento inicial do pinhão-manso, verificaram que houve efeito linear negativo das doses de potássio sobre todas as variáveis de crescimento estudadas. A área foliar foi a mais negativamente afetada por esse tipo de adubação, com redução de $20,48 \%$.

\section{CONSIDERAÇÕES FINAIS}

Os diferentes volumes dos biofertilizantes com urina de vaca e manipueira, influenciaram no crescimento das plantas de pinhão-manso durante os 360 dias, exceto na variável altura das plantas;

A aplicação de $1000 \mathrm{ml}$ do biofertilizante a base de urina de vaca, proporcionou incremento no diâmetro caulinar de 4,75 \%, no número de folhas de $18,70 \%$ e na área foliar de $236,53 \%$, quando comparados a testemunha;

O uso de $1000 \mathrm{ml}$ da calda com manipueira, proporcionou um aumento no número de folhas e na área foliar nas plantas de pinhão-manso de 53,48 \% e 414,02 $\%$, respectivamente, quando comparado ao menor valor obtido;

A interação da urina de vaca com $1000 \mathrm{ml} \mathrm{da}$ calda com manipueira proporcionou um incremento em diâmetro caulinar de 23,53 \% em relação ao menor valor e em área foliar de 543,01\%;

A interação manipueira com $1000 \mathrm{ml}$ do biofertilizante a base de urina de vaca, ocasionou um aumento de $22,5 \%$ e de $837,67 \%$ nas variáveis diâmetro caulinar e área foliar respectivamente, em relação ao menor valor. 


\section{REFERÊNCIAS}

ALBUQuerQue, F. A.; CASTRO, N. H. C. BELTRÃO, N. E. M., LUCENA, A. M. A.; SOUZA, S. L. FREIRE, M. A. O.; SAMPAIO, L. G. Análise de crescimento inicial do Jatropha curcas em condições de sequeiro. Rev. Bras. O1. Fibros., v.13, n.3, p. 99106, 2009.

ARRUDA, F. P. de; BELTRÃO, N. E. de M.; ANDRADE, A. P. de; PEREIRA, W. E.; SEVERINO, L. S. Cultivo do pinhão-manso (Jatrofa curcas L.) como alternativa para o semiárido Nordestino. Rev. Bras. O1. Fibros, v.8, p. 789-799, 2004.

BELTRÃO, N. E. de M. Relações satisfatórias: fertilidade do solo. [s.l.]: Embrapa Algodão, 2007.

CARDOSO, E. Uso de manipueira como biofertilizante no cultivo do milho: avaliação no efeito do solo, nas águas subterrâneas e na produtividade do milho. 2005. 49f. Dissertação (Mestrado em Ciências Ambientais) - Universidade do Extremo Sul Catarinense, Criciúma, SC.

CEZAR, M. N. Z; PAULA, P. D. de; POLIDORO, J. C.; RIBEIRO, R. de L. D.; PADOVAN, M. P. Efeito estimulante da urina de vaca sobre o crescimento de mudas de pepino, cultivadas sob manejo orgânico. Ensaios, Campo Grande, v. 11, n. 1, p.67-71, abr. 2007

CHAVES, L. H. G.; CUNHA, T. H. C. S.; BARROS JÚNIOR, G.; LACERDA, R. D. de; DANTAS JÚNIOR, E. E. Zinco e cobre em pinhão manso. Crescimento inicial da cultura. Revista Caatinga, v. 22, p. 94-99, 2009.

DRUMOND, M. A.; SANTOS, C. A. F.; OLIVEIRA, V. R.; MARTINS, J. C.; ANJOS, J. B.; EVANGELISTA, M. R. V. Desempenho agronômico de genótipos de pinhão manso no semiárido pernambucano. Ciência Rural, v. 40, p. 44-47, 2010.

EMATERCE. Urina de vaca: adubo e defensivo natural para o solo e plantas. Fortaleza, SRD, 2000. 3p. (Boletim Informativo).

EMBRAPA AGROENERGIA. Pinhão-manso: matéria prima potencial para produção de biodiesel. Ministério da Agricultura, Pecuária e Abastecimento. Brasília, DF, 2009. 
FERREIRA, E. A excreção de bovinos e as perdas de nitrogênio nas pastagens tropicais. 1995. 114f. Dissertação (Mestrado em Produção Animal) - Universidade Federal do Rio de Janeiro, Seropédica, Rio de Janeiro-RJ.

FIORETTO, R. A.; SANTOS, J. R.; BICUDO, S. J. Manipueira na fertirrigação: efeito sobre a produção de mandioca (Manibot esculenta Crantz.). Revista Brasileira de Mandioca, Cruz das Almas, BA, v.16, n.2, p.149-156. dez. 1997.

GADELHA, R. S, S. Agricultura orgânica: urina de vaca na produção de alimentos. A Lavoura. Rio de Janeiro, RJ. p. 14-17. 2001.

GUIMARÃES, A. S. Crescimento e desenvolvimento inicial do pinhão-manso (Jatropha curcas L.) em função de fontes e quantidades de fertilizantes. 2008. 92f. Tese (Doutorado em Agronomia) - Programa de Pós-graduação em Agronomia, Universidade Federal da Paraíba. 2008.

JARVIS, S. C.; HATCH, D. J.; ROBERTS, S. The effects of grassland managernent in nitrogen losses from grazed sward through ammonia volatization; the relationship to excretal N returns from cattle. Jornal or Agricultural Science Camb., n. 112, p. 205-216, 1989.

LARCHER, W. Ecofisiologia vegetal. Tradução C.H.B.A. PRADO. São Carlos: Rimas, 2004. 531p.

LAVIOLA, B. G.; DIAS, L. A. dos S. Teor e acúmulo de nutrientes em folhas e frutos de pinhão-manso. Revista Brasileira de Ciência do Solo, v. 32, p. 1969-1975, 2008.

LIMA, R. L. S.; SAMPAIO, L. R.; FREIRE, M. A. O.; CARVALHO JÚNIOR, G. S.; SOFIATTI, V.; ARRIEL, N. H. C.; BELTRÃO, N. E. M. Crescimento de plantas de pinhão-manso em função da adubação orgânica e mineral. In: CONGRESSO BRASILEIRO DE MAMONA, 4; SIMPÓSIO INTERNACIONAL DE OLEAGINOSAS ENERGÉTICAS, 1, 2010, João Pessoa, PB. Inclusão Social e Energia: Anais... Campina Grande: EMBRAPA Algodão, 2010, p. 528-534.

MALAVOLTA, E. O Futuro da nutrição de plantas tendo em vista aspectos agronômicos, econômicos e ambientais. Informações Agronômicas, Piracicaba, n. 121, 2008.

MARTINS, C. C.; MACHADO, C. G.; CAVASINI, R. Desenvolvimento inicial de mamona 
e pinhão-manso em solo submetido a diferentes corretivos e doses de fósforo. Revista Verde de Agroecologia e Desenvolvimento Sustentável, v.5, p.143-150, 2010.

MEDEIROS, M, B.; LOPES, J. S. Biofertilizantes líquidos e sustentabilidade agrícola. Bahia Agrícola, v. 7, n. 3, nov. 2006.

MEDEIROS, K. A. A. de L.; SOFIATTI, V.; SILVA, H.; LIMA, R.; LUCENA, M. A. de; VASCONCELOS, G. C.; ARRIEL, N H. C. Mudas de pinhão manso (jatropha curcas L.) produzidas em diferentes fontes e doses de matéria orgânica. In: CONGRESSO BRASILEIRO DE MAMONA, 4; SIMPÓSIO INTERNACIONAL DE OLEAGINOSAS ENERGÉTICAS, 1, João Pessoa, PB. Anais... Campina Grande: EMBRAPA Algodão, 2010. p. 1413.

NASCIMENTO, J. J. V. R. do; OLIVEIRA, S. J. C.; AXEVEDO, C. A. V. de; NOBREGA, J. A. da; TAVARES, M. J. V. Influência da adubação nitrogenada no crescimento inicial do pinhão manso (Jatropha curcas L.). In: CONGRESSO DE INICIAÇÃO CIENTÍFICA DA UNIVERSIDADE FEDERAL DE CAMPINA GRANDE, 2008. Anais... Campina Grande: UFCG, 2008.

NASCIMENTO, J. J. V. R. do; NÓBREGA, J. A. da; REBEQUI, A. M.; NOBREGA, J. A. da; N.; AZEVEDO, C. A. V. de, ALVES, G. S. Adubação fosfatada no crescimento inicial do pinhão manso. In: CONGRESSO BRASILEIRO DE MAMONA, 4; SIMPÓSIO INTERNACIONAL DE OLEAGINOSAS ENERGÉTICAS, 1, João Pessoa, PB Anais... Campina Grande: EMBRAPA Algodão, 2010. p. 1413; p. 425.

OLIVEIRA, R. B. de; GIMENEZ, V. M. M.; GODOY, S. A. P. de. Intoxicações com espécies da família Euphorbiaceae. Revista Brasileira de Biociências, v. 50, p. 69$71,2007$.

OLIVEIRA, A. P. de; PAES, R. de A.; SOUZA, A. P. de; DORNELAS, C. S. M.; SILVA, R. A. da. Produção de pimentão em função da concentração de urina de vaca aplicada via foliar e da adubação com NPK. Agropecuária Técnica, v. 25, n. 1, 2004.

PESAGRO-RIO. Urina de vaca: utilização em vegetais. 1999. (Folder).

PESAGRO-RIO - EMPRESA DE PESQUISA AGROPECUÁRIA DO ESTADO DO RIO DE 
JANEIRO. Urina de vaca: alternativa eficiente e barata. Niterói, 2001. 8p. (PESAGRORIO. Documento, 68).

SAS INSTITUTE. SAS/STAT software: changes and enhancements through release 6.12. Cary: Statistical Analysis System Institute, 1997. 1167p.

SCHIAVO, J. A.; SILVA, C. A.; ROSSET, J. S.; SECRETTI, M. L.; SOUSA, R. A. C.; CAPPI, $\mathrm{N}$. Composto orgânico e inoculação micorrízica na produção de mudas de pinhãomanso. Pesquisa Agropecuária Tropical, v. 40, p. 322-329, 2010.

SUJATHA, M.; MAKKAR, H. P. S.; BECKER, K. Shoot bud proliferation from axillary nodes and leaf sections of nontoxic Jatropha curcas L. Plant Growth Regulation, v.47, p.83-90, 2009.

SILVA, F. F. da; BERTONHA, A.; FREITAS, P. S. L. de; MUNIZ, A. S.; FERREIRA, R. C. Aplicação de cinza da casca de arroz e água residuária de fecularia de mandioca na cultura de aveia. Revista Agronegócio e Meio Ambiente, v.1, n.1, p. 25-36, jan./ abri. 2008.

SOUZA, J. T. A.; FARIAS, A. L. de; FERREIRA, A. S.; OLIVEIRA, S. J. C. Avaliação da fitomassa epígea e hipógea em mudas de mamoneira (Ricinus communis L.) sob diferentes dosagens de urina de vaca. In: CONGRESSO BRASILEIRO DE MAMONA, 4; SIMPÓSIO INTERNACIONAL DE OLEAGINOSAS ENERGÉTICAS, 1, 2010, João Pessoa, PB. Inclusão Social e Energia. Anais... Campina Grande: EMBRAPA Algodão, 2010, p. 446-449.

TAIZ, L.; ZEIGER, E. Fisiologia Vegetal. 4. ed. Porto Alegre: Artmed, 2013. 719 p. II.

VIETES, R. L.; BRINHOLI, O. Utilização da manipueira como fonte alternativa a adubação mineral na cultura da mandioca. Revista Brasileira de Mandioca, Cruz das Almas, v. 13. n. 1, p. 61-66, 1994.

Recebido em: 22 de setembro de 2014 Aceito em: 21 de janeiro de 2016 